\title{
Erratum to: Micro-fabricated perforated polymer devices for long-term drug delivery
}

\author{
Zhuo-Jie Wu • Zhiquan Luo • Ashish Rastogi • \\ Salomon Stavchansky • Phillip D. Bowman • Paul S. Ho
}

Published online: 6 April 2011

(C) Springer Science+Business Media, LLC 2011

Erratum to: Biomed Microdevices

DOI 10.1007/s10544-011-9516-8

In the original version of this article unfortunately one of the coauthor was spelled incorrectly. He should be listed as "Ashish Rastogi" instead of "Ashish Rastogia"

The online version of the original article can be found at http://dx.doi. org/10.1007/s10544-011-9516-8.

Z.J. Wu $\cdot$ Z. Luo $\cdot$ P. S. Ho $(\bowtie)$

Microelectronics Research Center,

The University of Texas at Austin,

Austin, TX 78758, USA

e-mail: paulho@mail.utexas.edu

A. Rastogi $\cdot$ S. Stavchansky

Division of Pharmaceutics, College of Pharmacy,

The University of Texas at Austin,

Austin, TX 78712, USA

A. Rastogi • P. D. Bowman

U.S. Army Institute of Surgical Research,

San Antonio, TX 78234, USA 